\title{
Business Model Construction from Dynamic Capabilities Perspective
}

\author{
Xiong Wang ${ }^{1} \&$ Sarana Photchanachan ${ }^{2}$ \\ ${ }^{1} \mathrm{Ph}$. D. Candidate, School of Management, Shinawatra University, Pathum Thani, Thailand \\ ${ }^{2}$ Management, School of Management, Shinawatra University, Thailand \\ Correspondence: XiongWang, Management, School of Management, Shinawatra University, Thailand.
}

Received: October 4, 2021

Accepted: October 25, 2021

Online Published: November 5, 2021

doi:10.5539/ibr.v14n12p57

URL: https://doi.org/10.5539/ibr.v14n12p57

\begin{abstract}
The construction of the business model is to shape the structure of various activities in the plate according to the task attributes and task objectives of each section in the business model. The Dynamic Capabilities of the enterprise determine the result of the construction of the business model, and its strength also affects the adaptation and operation of the business model institutions to the new business model. Enterprises with strong Dynamic Capabilities have a good execution ability in the business model architecture, and can also quickly adapt to the structural framework of changing their business model, and improve the feasibility of the actual operation of the business model. This paper will be in the framework of the Dynamic Capabilities theory, the construction of business model, through the case from model construction, design innovation to the coordinated operation of the new model, concluded that the two have a strong interaction, including the enterprise higher-order Dynamic Capabilities has a strong positive influence on the choice of business model, construction and application.
\end{abstract}

Keywords: dynamic capabilities, business model, innovation

\section{Introduction}

The business model is the enterprise as the core of the stakeholders to complete the two basic tasks of "creating customer value" and "acquiring enterprise interests".As Joan Magretta, a famous scholar at Harvard University pointed out: business models are the story of how innovators make money, and the idea of the business innovation building activities to carry out. Creating customer value is the premise and basis of obtaining enterprise interests. Without considerable enterprise interests, there cannot be sustainable resource conditions. Specifically, a good business model will not depend solely on customer value or the enterprise interests, but on the part created together, the larger, the more outstanding the business model.

According to the global entrepreneur survey structure conducted by The Economist, more than half of the global respondents believe that business model innovation is more important than product or service innovation. The more representative entrepreneurial model experimental innovation exploration comes from a 2010 study published by Dr. Sosna, which states that the successful innovation construction of the business model is a continuous trial and error, the learning process. The starting point of this process is the overall plan of a new business, starting from the two stages to finally complete the innovative construction of a business model, these two stages are the development of the original model includes the design and optimization of the original model, and the expansion stage includes scale amplification and consolidation and improvement.

According to the basic idea of Porter's competition strategy theory based on the Mason-Bain paradigm, where resource-based view states that only four strategic resources can be integrated under the VRIN framework (Valuable, Rare, Imperfectly Imitable, Non-Substitutable). The cooperation between VRIN resources and the business model largely depends on the support of enterprise Dynamic Capabilities. In the process of critical inheritance and development of resource foundation theory, Dynamic Capabilities theory explains how its ability determines the design and operation of business model, and its higher-order Dynamic Capabilities is a necessary condition for business model design, optimization, operation, and transformation.

Dynamic Capabilities plays an important role in maintaining the high profitability of the enterprise from multiple links, among which the ability to design and adjust the business model is an important link.

Dynamic capability functions at two levels from the perspective of the overall capability combination of the 
organization (Winter 2003): the underlying capability layer and the dynamic capability layer. The basic management ability of the enterprise is usually manifested in the daily operation of the daily activities, management, and organization work of personnel. These abilities can enable the enterprise to implement clear production and operation activities such as specific production projects daily. On top of these underlying capabilities is enterprise dynamic capabilities, which can be divided into two parts: micro basic capabilities and higher-order dynamic capabilities (higher-order capabilities) (Teece, 2007).

The micro basic capabilities of dynamic capabilities can adjust and reconstruct the existing basic capabilities of enterprises, while promoting enterprises to develop new capabilities, such as developing new products, expanding sales areas, cross-departmental product task allocation in large companies, and fine decision making in uncertain environments. And higher-order Dynamic Capabilities to guide these micro basic ability: reflected in the enterprise is good at thinking of customer value proposition, to design a business model to solve customer problems, its scheme and according to the existing organization form and development plan to choose the best configuration of organizational structure to achieve the best resources transformation, and finally determine the interests of the enterprise.

This paper discusses the design, construction, and operation of the business model under the framework of Dynamic Capabilities theory, focusing on the conception value, design scheme, and transformation benefit ability of the senior managers of enterprises who attach the most importance (or attention).

\section{Business Model}

The definition of the business model does not have a unified view.

The definition of the business model does not have a unified view. To put it simply, the business model is the profitable mode of the company's operation, including the positioning of customers and their pain points, the design of products or services to solve the pain points, and the scheme for the company or enterprise to make profits. Business model generally means the plan implemented by a company to make a profit and generate revenue from operations. It composes the components and functions of the business, as well as the revenues and expenses. In other words, it explains how a company can get the values in the market. A consulting firm MKLab. Inc. defines the business model as - a description of how your company intends to create value in the marketplace. It includes that unique combination of products, service, image, and distribution that your company carries forward. It also includes the underlying organization of people and the operational infrastructure that you use to accomplish their work (Chesbroug \& Rosenbloom, 2002).

Although academia did not form a unified view of what business model is, Zott (2011) found some common themes of business model research: 1) business model, as an emerging analysis unit, was used by scholars to study business operation. 2) business model emphasizes the system level, that is, with comprehensive methods to explain how companies do business. 3) focus enterprises and external partners play an important role in the business model, business model explains how enterprises do value creation and value capture. The business model, therefore, describes the system of interdependent activities performed by the focus company and its partners and the mechanisms which link those activities to each other. Activities in the Focus company's business model can be seen as the participation of human, material, and capital resources of either of the business model (Focus company, end customers, suppliers, etc.) to serve the specific purpose of achieving the overall objective (Zott and Amit,2011). Therefore, Zott and Amit proposed the concept of business model is universal, Amit and Zott (2006) reveal business model from the organizational perspective that the essence of business model is a combination of activities across organizational boundaries for stakeholders to create value for customers, suppliers, employees, and partners, namely business model is the design of focus enterprises and external stakeholders in transaction content, transaction structure, and transaction governance, the business model can create value for stakeholders.

Based on the literature update and summary in recent years, this article adopts the Teece (2010) definition of the business model: the value creation, value delivery, value capture mechanism design, or architecture adopted by the company. The essence of a business model is how companies deliver value to customers, induce customers to pay for it, and turn customer payments into corporate profit. In other words, the most important function of a business model is to identify unmet customer needs in the market, provide the corresponding technology and organization to meet these needs, and profit from the above activities. For for-profit enterprises, the business model of value creation, delivery, and capture cannot operate in the long term.

Osterwalder \& Pigneur (2010) have comprehensively summarized the components of the business model, although similar, they divide the business model components into three main categories: 1) Customer value (customer positioning, customer pain points, products and services, environment); 2) profit model (output 
pricing, sales, customer interaction); 3) company cost (core assets, operating activities, external cooperation network). The Components of a business model should be internally unified and consistent (Ritter, 2014) rather than a random accumulation of components. The organization's general capabilities should support the customer needs goals set by decision-makers. And the business model needs a management structure and core resources that match it.

\section{Dynamic Capabilities}

Dynamic capabilities include the ability to identify and judge new business opportunities, the ability to form new customers, the ability to build and improve the business model and make enterprises make a profit. They can help enterprises improve their regular capabilities by adjusting and integrating resources, and jointly direct their regular capabilities to the capabilities of their partners. In response to the variability in the business environment and market position, enterprises need to mobilize the corresponding capacity development and coordinate the balance of resources of companies and partners to solve the new problems encountered and thus better adapt to the constantly updated external environment.

The company's Dynamic Capabilities determine the resource integration efficiency and related costs. The effective resource integration mentioned here mainly combines the company's business model with its customer problems. To achieve this goal, organizations must be able to continuously grasp the customer value proposition and regularly design to improve the business model transformation, to be able to actively adapt when new threats or opportunities arise.

Dynamic capabilities are diverse, and an enterprise does not need to improve them comprehensively to obtain the strongest dynamic capabilities. In reality, a company is highly sensitive to new opportunities but cannot relatively recognize customer value propositions and develop new business models. At this time, it only needs to improve its lacking ability.

In most cases, management power is one of the key elements of dynamic capabilities that can help businesses seize new opportunities (Teece, 2007). The concept of management capacity has developed into a subfield of dynamic management capacity (dynamic managerial capabilities) over the past decade, and the Economist survey also shows that business model innovation is more important than product or service innovation. In today's Internet era, it may even be the most important component of enterprise dynamic management capabilities.

\section{Business Model in the Framework of Dynamic Capabilities}

In addition to clarifying the definition of a business model, its distinction from relevant concepts is also worth careful study. In some definitions, business models cover strategic analysis, such as those proposed by Chesbrough \& Rosenbloom in a study in 2002. However, Teece (2010) argues that while strategic analysis is closely related to business model design, the business model is a behavior model that can be analyzed separately and in more detail. Unlike any management in the traditional sense, the business model is the enterprise to create a small environment exclusive to its own, and this environment will relax or shrink as the general environment changes. The enterprise needs to have faster and earlier adaptation and adjustment, which is the business model under strategic analysis. After strategic analysis, there is the choice of specific business model, market segment, better than competitors.

Casadesus-Masanell \& Ricart (2011) argue that after strategic analysis, old business models are often replaced by new ones to gain or maintain a clear dominant enterprise in the market. They also make it clear that strategy has been a major component of competitiveness over the past three decades. Now, the corporate pursuit of a sustainable advantage begins with the business model. This paper believes that enterprise unique capabilities, namely core resources, should be a major component of their competitiveness because these capabilities enterprises can conduct a strategic analysis of closely related business model design.

In the majority of the traditional model, the core resources of the enterprise determine the enterprise strategy, and the enterprise strategy determines the design of the business model. However, with the progress of The Times, new general technologies such as the Internet, not only create opportunities for a new business model but also the enterprise strategy must serve the new business model. In this case, the business strategy changes once the new business model is established and brings new restrictions or guidance to the future actions of the business. The business model reflects the profit degree of the enterprise, which also affects the feasibility of the enterprise strategy. If their strategy and business model conflict, companies should choose between both. The framework diagram that takes high-order dynamic capability as the core of the enterprise well reflects the interdependence between dynamic capability and strategy. Figure 1 describes the brief structure without considering the feedback 
channels. By combining dynamic capabilities with the strategy to create and refine a defensible business model to guide organizational change, would ideally generate enough profits to continuously improve capabilities and gain benefits.

Rumelt(1984) is necessary to recognize a general analysis of the strategy to identify isolation mechanisms to prevent competitor imitation. There are many such strategies, such as using patents and trade secrets to protect corporate core resources to put costs into increased customer engagement, expanding quickly to ensure market share and cost advantage. There is no strategy once and for all, like the Chinese enterprise drops taxi and fast taxi competition, if the hitchhiker as customers, their work dynamic, they did not terminate after a taxi, maybe they will be shopping, eating, cannot strategy only on the taxi competition, for customer subsequent related problems can make the appropriate supplement, increase the unique value of the enterprise, is also the embodiment of enterprise high Dynamic Capabilities.

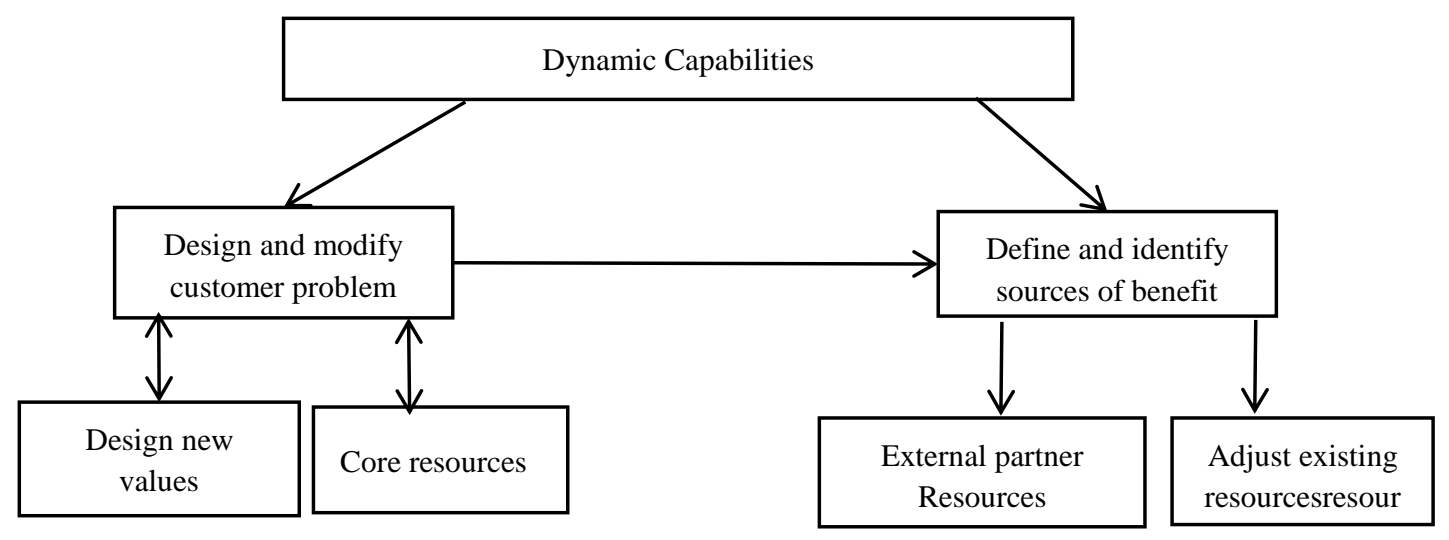

Figure 1. dynamic capabilities and business model building

\section{Interaction of Business Model and Dynamic Capabilities}

The relationship between business model and Dynamic Capabilities, the business model is supported by Dynamic Capabilities, is manifested in a dynamic capable organization can quickly implement, test, and improve a new or modified business model. Its success depends on the perfect management architecture design, integrated regulatory resources, and learning capabilities that are the core of dynamic capabilities. On the other hand, dynamic capability also relies on organizational flexibility determined by the business model, and which business model it chooses largely affects the organizational flexibility,

\subsection{Importance of Dynamic Capabilities for Business Model Building}

The management's ability to develop and refine a business model is the micro basis of dynamic capabilities (Teece, 2007), in the same of designing a brand new business model. For enterprises, especially innovative enterprises, the first step is to establish a relationship between customers and enterprises. The stronger the relationship, the greater the customer value storage that can be mined, and the "pain points" of customers, because they are willing to pay for products or services that can solve their problems. A successful business model provides a custom solution that usually achieves high enough to cover costs and makes significant profits. For the most part, the development of this business model begins with a deep understanding of customer "pain points" and insight into the dozens of business models that already exist.

Creating a brand new business model is difficult. The new business model is periodically presented along with the progress of social and technological technology. The O2O model produces a large number of such innovations. As a result, many industries are partially or completely online by online companies. Today, the Internet can create new business models and also provides a suitable development environment for these business models. At the same time, with the Internet model, new "pain points" problems, such as Stitch Fix in the United States, the company founded in 2011 to quickly make the most suitable clothes for users through unique data analysis technology. The company targets an urban professional elite of around 25, who loves fashion and is busy, and its online service for the issue is so popular with this new business model.

Business model innovation usually takes a certain amount of time to catch up with the development of technology, which is also because the social environment also needs to slowly apply new technologies, and the 
business model has a high dependence on the social environment, and the society needs time to adapt to the development of new technologies. Modern new business model innovation is accompanied by the emergence of the Internet of Things. In the past, independent items had different characteristics. For example, customers can choose vehicles, including vehicles, personnel, and traffic environment. Similarly, enabling companies to quickly learn how customers use the product, for example, to help them thus establish a usage-based rental model rather than one-time sales, such as the airport car rental business. Furthermore, the large amount of data acquired by sensors throughout the Internet of $\mathrm{T}$ forms a new data resource that can be used to sell them or as a basis for internal business model adjustments and major activities.

Most "new business models" will have similarities to the old ones, often manifested as rearranging existing models or adding one or more combinations of conditions. A typical example is "love driving", which seeks and contacts the nearest driver to you online when the customer can not drive after the drink and sends you to the destination. The same company usually provides a certain share of the errands business in non-meal points. The possibility of a business model restructuring is almost endless.

From a practical perspective, the strength of a company's dynamic capabilities determines the size of its optional range. Companies with less dynamic capabilities are more likely to rely on previous business models and cannot design and implement new models. Instead, If a company has excellent dynamic capabilities, businesses are freer to dive into some business models that need to revolutionize resources or activities.

Building a new business model is a process of continuous trial and error, so only by relying on the Dynamic Capabilities of the enterprise combined with the components of the existing business model, can we build a "new" business model in line with the development of the enterprise itself. It can also be seen that the components of an enterprise business model, although not appearing on their balance sheet, can be said to be an important asset (Teece,2015) of the organization. In the reconstruction of business models, adjustment and modification are usually indispensable steps, and the Dynamic Capabilities can realize the partial modification reconstruction of the mode in the multi-module context while trying to ensure that the other parts are not affected.

Replacement of business model components will follow the enterprise trajectory. A typical example is the component replacement or even completely changed the decision to produce or buy. The shift from "manufacturing" to "buying" maybe because the advantages of conducting production activities within the organization faded over time, from "buying" to "manufacturing" probably because previously outsourced activities are already strategically important, just as Nike, actually Nike has transformed from manufacturing to a service company that outsources all manufacturing to other companies to reduce costs, while it provides product design and subsequent customer service.

\subsection{Influence of Design New Value and Knowledge Assets on Business Model}

\subsubsection{Influence of Design New Value on Business Model and Dynamic Capabilities}

Another embodiment of the coupling relationship between business model and dynamic capabilities is the new value design. Leih et al. (2015) believe that adopting a specific business model requires organizations to meet multiple conditions. To quickly implement and adapt a new business model requires strong dynamic capabilities, while its business model is designed with innovation and flexibility. Actually "having everyone think that he not only has the right and the responsibility to find and achieve new opportunities" is perhaps the most important job for business managers (McGrath and MacMillan,2000), not one-time but long-term work. Path-Dependence is a specific phenomenon found by economists when exploring the laws of the institutional evolution process, and it is also an easy trend in the development of enterprises because managers usually aim at constantly improving existing models rather than creating new ones. Therefore, to avoid organizational rigidity, the form to find new value should become a semi-persistent activity habit.

After choosing a business model, the corresponding management needs to decide which activities are launched by the enterprise itself, and which activities need to be undertaken or directly outsourced by the business partners. In the decision of "production or purchase", the core resources of the enterprise are the primary consideration, and the positioning is to design and determine the unique resources to be developed and utilized by the enterprise according to the planning and design of the enterprise.__ "bottleneck assets" obtained according to Professor Teece $(1986,2006)$ are key to value capture. While for activities that can be competitively provided by external collaborators and special knowledge cannot be extracted from it, outsourcing should be achieved with sufficient internal resources to effectively manage this relationship.

The second advantages of working with an outside company are that companies can devote more resources to 
their activities to help fine-tune the company's day-to-day operational capabilities. Enterprises promote enterprise unbundling through the digital revolution, and Cloud computing sharing platforms are a good example of a lot of competitive businesses in providing interoperability data for basic products or services. By utilizing this resource for non-sensitive computing tasks, companies can get rid of maintaining their servers for non-critical data processing, which is also a way of interaction costs. This allows the company's digital processing resources to commit major activities.

Hagel III, an expert in reshaping strategy, has proposed four steps for those enterprises in modern society, first, a credible and attractive vision, and second, a platform, which refers to a certain collection of resources to share. Even if you build up confidence through a great vision, you always have to have basic "ammunition equipment."The platform is the second encouragement that remodelers offer to future allies beyond their vision. The third is a special investment, with this step to make the changes of the whole process more professional and efficient. It also gives confidence to the allies. Fourth, we will improve and consolidate this new model.

\subsubsection{Dynamic Capabilities and Core Resources Impact on Business Models}

A range of core issues in building a business model all involve the control and use of core resources. Core resource positioning refers to the unique resources that need to be designed and determined by the processing system developed and utilized by the enterprise. These resources play an important and irreplaceable role in ensuring the processing system completes planned output with quality and quantity.

There are many types of core resources, Different types of core resources play different roles in supporting process operations, But it has three important attributes. First is output quality support, Such as creative and design capabilities as core resources for service-oriented processes, The second is unique, James Martin, a famous administrator, and process innovation authority, said that " Actually, Knowledge is not a power, Only unshared knowledge is the source of power ", For example, when research entities have strong intellectual property rights, It can often adopt a "license" as a business model, Even if licensees will split most of their interests, especially when businesses have strong patent rights, License is seen as a potentially viable business model, Because if you want to continue developing along with the existing patents, Establishing the necessary supporting facilities is expensive and the short execution time is available before being overtaken by competitors. The third is high-yield redundancy. The operation of the core process is based on the use of all kinds of relevant resources, especially core resources. High-yield redundancy refers to the consumption potential of core resources. To simply put, it is the products provided by enterprises or related that can ensure the completion of quality, time, and quantity.

Companies can also have multiple core resources at the same time, where a comprehensive business model is feasible, for purely electronic digital products, or venture capitalists willing to provide the necessary investments. Google's business model, for example, is to offer search engine services to customers for free and profit through targeted advertising, data collection, and data sales. Similarly, radio, television, and terrestrial broadcasting (excluding satellite broadcasting) have always served audiences and listeners, while making profits from advertisers. Long-term print newspapers and magazines adopt a mixed business model where subscribers pay less than the cost of printed materials while advertisers pay for the difference.

The formation path of some resources is relatively simple, or more regular (theoretically, the structural characteristics of this path are obvious), so the learning imitation of such resources on the laziness of its formation path is not significant. Type resources: machine and equipment, buildings, its forming path depends on the corresponding manufacturing technology, the installation process. Once these technologies and processes are mastered, it means that the forming path of these resources is clear, with the possibility of replication. Other resource forming paths are very complex and highly personalized. This is similar to the human soul, if the soul is regarded as a resource, the molding process is different, to replicate the same soul, the need to repeat the growth path of the emulated. This resource includes hidden knowledge resources such as know-how, patented technology, and excellent corporate culture.

In practice, in a business model with patents as the core resource, the license fee is only a small source of the company's revenue. The answer to this question seems to be that it is almost impossible for most businesses to implement an integrated business model across multiple verticals at once. Even if the capital markets develop well, this weakens the return opportunities for corporate interests. Whether it is strategic alliances or business ecosystem, for enterprises, building such a cooperation system, or gathering such cooperation resources, usually need to go through a more complex process. This is due to the need that enterprises can better support customer problem solutions, the same right support for cost reduction demand, such as objectively limited energy and resources in the face of the above problems, let alone bear the high cost of applying it to multiple verticals. To 
provide products and services to the service objects, enterprises need to purchase relevant raw materials, collaborative parts, or finished products. The quality of products and services of enterprises depends on these purchased products and services, but the resources of the enterprise itself are limited. Since most of the purchased products and services are vertical fields, it is unlikely to complete a series of challenges with its ability. Therefore, find collaborators to serve businesses to ensure optimal operating costs.

Therefore, compared with the enterprise benefits brought by technological innovation, the income that enterprises can get from patents and other resources is very limited. Because its income does not reflect its value to the society, so compared with the optimal level of the society, enterprises are always in the state of insufficient return. A similar situation can be seen in Japanese anime production companies, animation playback rights apply different use rules in different regions for licensing activities. Some judiciary prefers to protect the rights of TV channels, but not in some areas. In this environment, business models that rely mainly on playback licensing are largely limited by their ability to capture value when compared to those that rely on Internet playback.

It can be seen that there should be an excellent business model, that is, it can not only adapt to the constantly changing business environment but also conform to the constantly adjusted social changes and regional policies. Enterprises very much need dynamic capabilities to complete mode construction and adjustment. Having a common business model can be said to be an asset of the enterprise, However, to choose, debug and match the business model with the environment is the embodiment of the enterprise Dynamic Capabilities.

\section{Discussion}

This paper emphasizes the coupling relationship between some business models and dynamic capabilities, at its core are powerful dynamic capabilities that help build and implement efficient business models. It also discusses how core enterprise resources influence dynamic capabilities to further affect the efficacy of business models. A good business model, by making smart "make or buy" choices, can free up more resources to invest in future business development and help an organization reorient its strategic focus. When the change of enterprise business model is transformed into the change of organizational form, the dynamic capability of the company will also change. It is not impossible to create a new business model based on the existing business, and then to realize the effective coordination between the new business structure and the operation model requires excellent asset allocation skills.

The following are some summaries of this research:

(1) A good business model depends not only on science and analysis, but also on basic management skills and enterprise dynamic capabilities; (2) To build an excellent business model, it is necessary to have a deep understanding and accumulation of customer needs, and at the same time, it must have the resources to solve customer problems; (3) All good business models need to be based on an understanding of the current business models operating in the market because even the latest business model design includes the use of a mixture of old model modules; (4) Focusing on solving a customer problem and maintaining consistent behavior naturally reinforces business model components; (5) Strategic analysis can not lack business model design. Because strategic analysis guides the direction of business model design, it is also affected by the old business model to a certain extent. (6) When the business model is combined with strategy and core resources, it has a certain anti-imitation ability. (7) First of all, it is a crucial ability to recognize the customer base to be locked and the "pain points" of customers; (8) When it comes to external partners, it is extremely important to consider the cost of interaction as early as possible and effectively; (9) The ability to reinvent a successful business model is one of the key elements of the dynamic ability to capture revenue.

\section{References}

Barney, J. B. (1991). Firm resources and sustained competitive advantage. Advances in Strategic Management, 17(1), 3-10. https://doi.org/10.1016/S0742-3322(00)17018-4

Casadesus-Masanell, R., \& Ricart, J. E. (2011). How to design a winning business model. harvard business review.

Chesbrough, H., \& Rosenbloom, R. S. (2002). The role of the business model in capturing value from innovation: evidence from xerox corporation's technology spin-off companies. Social Science Electronic Publishing, 11(3), 529-555. https://doi.org/10.1093/icc/11.3.529

Cooper, M. C., Lambert, D. M., \& Pagh, J. D. (1997). Supply chain management: more than a new name for logistics. International Journal of Logistics Management, 8(1), 1-14.

https://doi.org/10.1108/09574099710805556 
Fletcher, T. D., Andrieu, H., \& Hamel, P. (2013). Understanding, management and modelling of urban hydrology and its consequences for receiving waters: a state of the art. Advances in Water Resources, 51(JAN.), 261-279. https://doi.org/10.1016/j.advwatres.2012.09.001

Hagel, J., Brown, J. S., \& Lang, D. (2008). Shaping strategy in a world of constant disruption. Harvard Business Review. https://doi.org/10.1177/1059601108324879

MacMillan, I. C., Mcgrath, G., \& Rita. (2000). The entrepreneurial mindset: strategies for continuously creating opportunity in an age of uncertain. Harvard Business School Press Books.

Magretta, J. (2002). Why business models matter. Harvard Business Review, 80(5), 86-92. https://doi.org/10.2469/faj.v58.n3.2544

Sosna, M., RN Trevinyo-Rodríguez, \& Velamuri, S. R. (2010). Business model innovation through trial-and-error learning: the naturhouse case. Long Range Planning, 43(2-3), 383-407. https://doi.org/10.1016/j.lrp.2010.02.003

Teece, \& David, J. (2016). Dynamic capabilities and entrepreneurial management in large organizations: toward a theory of the (entrepreneurial) firm. European Economic Review, 202-216. https://doi.org/10.1016/j.euroecorev.2015.11.006

Teece, D. J. (1986). Profiting from technological innovation: implications for integration, collaboration, licensing and public policy. Research Policy, 15. https://doi.org/10.1016/0048-7333(86)90027-2

Teece, D. J. (2009). Business models, business strategy and innovation. Long Range Planning, 43(2-3), 172-194. https://doi.org/10.1016/j.lrp.2009.07.003

Teece, D. J. (2010). Explicating dynamic capabilities: the nature and microfoundations of (sustainable) enterprise performance. Strategic Management Journal, 28(13), 1319-1350. https://doi.org/10.1002/smj.640

Teece, D. J. (2015). Intangible assets and a theory of heterogeneous firms. Springer International Publishing. https://doi.org/978-3-319-07532-7

Winter, S. G. (2003). Understanding dynamic capabilities. Strategic Management Journal, 24(10). https://doi.org/10.1002/smj.318

Zott, C., Amit, R., \& Massa, L. (2011). The business model: recent developments and future research. Social Science Electronic Publishing, 37(4), 1019-1042. https://doi.org/10.2139/ssrn.1674384

Zott, C., Amit, R., INSEAD, \& Here, C. (2006). Business Model Design and the Performance of Entrepreneurial Firms (RV of 2003/94/ENT/SM/ACGRD 4).

\section{Copyrights}

Copyright for this article is retained by the author(s), with first publication rights granted to the journal.

This is an open-access article distributed under the terms and conditions of the Creative Commons Attribution license (http://creativecommons.org/licenses/by/4.0/). 